\title{
The Rationale for the Use of Modified Bitumen Coated Overburden Rocks for Haul Roads of Coal Mines
}

\author{
Sergey Ivanov ${ }^{1, *}$, and Nikita Martel $^{1}$ \\ ${ }^{1}$ T.F. Gorbachev Kuzbass State Technical University, 650000, Kemerovo, Russian Federation
}

\begin{abstract}
Kuzbass is a leader in the field of mining of coal as one of the main materials for industry and civilian use. Its production rate its is constantly increasing, which can not but affect the problem of using secondary material (in particular, rocks that are not used in further construction) that is produced during coal mining. Overburden rocks are often stored in dumps or they are used for filling coal mine roads, although this is the problem. In terms of their physical and chemical composition, the overburden rocks are of low strength, so there is a problem of strengthening this type of material, the solution of which can be found in the processing of rocks used for further construction with modified bitumen. The analysis of the effect of the adhesion ability of construction bitumen and crumb rubber modified bitumen produced according to the technology of stage addition of rubber crumb to bitumen (bitumen modified with crumb rubber by stages) is described in the article. Examples of the adhesion of construction bitumen and bitumen modified with crumb rubber by stages to various rocks are given. The characteristics of the adhesion ability of bitumen modified with crumb rubber by stages are substantiated.
\end{abstract}

\section{Introduction}

The technologies of modifying bitumen with rubber crumb today are becoming more and more widespread, aided by the task of increasing the service life of asphalt concrete pavements and finding ways to effectively utilize used automobile and aircraft tires. However, the absence of a theoretical model explaining the influence of various factors on the efficiency of the process of modifying bitumen with crumb rubber, leads to the fragmentation of research results and the ambiguity of the recommended process variables proposed by various authors.

In world practice, two main technologies for modifying bitumen with rubber crumb are considered: relatively low $\left(160 \ldots 200^{\circ} \mathrm{C}\right)$ process temperature technologies without any special requirements for mixing facilities [1-9] - the Asphalt Rubber method and increased (200 ... $260^{\circ} \mathrm{C}$ ) process temperature technology using special mixers - the Terminal Blended method [10-12]. Combined methods are also proposed when the process temperature corresponds to the

\footnotetext{
*Corresponding author: isa.ad@kuzstu.ru
} 
interval characteristic of the Terminal Blended method, and the use of high-speed mixers is not required.

\section{Materials and methods}

The use of various methods of modifying bitumen with rubber crumb certainly gives a positive result, which is expressed in an increase in the softening temperature using the Ring and Ball method, a decrease in the Fraas brittleness temperature, an increase in the binder elasticity, etc. Since bitumen, as a material, is most applicable in road construction, one of the main physical and mechanical parameters that increase the life of asphalt concrete layers of roads is the adhesive ability of the binder, that is, the adhesion of the modified bitumen to the surface of the used rocks.

The Kemerovo region grounds are mainly composed of sedimentary rocks, and as you know, bitumen is known to be an acidic medium, which in turn interacts rather inefficiently with the above mentioned ones. In this regard, it was necessary to evaluate the adhesive ability of the produced binder with the most popular rocks mined in the Kemerovo region.

\section{Results}

As a result, the most popular local rocks used in the construction of highways were chosen: 2-5 $\mathrm{mm}$ fraction Koelginskoe deposit white marble according to GOST 11508-74; 5-20 mm fraction Gurievskiy quarry crushed stone; $5-20 \mathrm{~mm}$ fraction $\mathrm{OOO}$ "Krapivinsky quarry" crushed stone; $5-10 \mathrm{~mm}$ fraction Berezovskiy quarry crushed gravel according to GOST 12801. Using these materials, the adhesive capacities of BND 90/130 bitumen and bitumen modified with crumb rubber by stages were compared.

The results of the tests for determining the quality of adhesion between bituminous binder and rock surface and their chemical composition are shown in Tables 1 and 2, as well as in Figures 1 and 2, respectively.

Table 1. Chemical composition of rocks.

\begin{tabular}{|c|c|c|c|c|c|c|c|c|c|c|c|c|c|}
\hline \multirow{2}{*}{ Rock } & \multicolumn{10}{|c|}{ Components, \% } \\
\cline { 2 - 12 } & $\mathbf{S i O}_{2}$ & $\mathbf{A l}_{2} \mathrm{O}_{3}$ & $\mathbf{F e}_{2} \mathrm{O}_{3}$ & $\mathbf{F e O}$ & $\mathbf{T i O}_{2}$ & $\mathbf{C a O}$ & $\mathbf{M g O}$ & $\mathbf{N a}_{2} \mathbf{O}$ & $\mathbf{K}_{2} \mathbf{O}$ & $\mathbf{S O}_{3}$ & $\mathbf{P}_{2} \mathbf{O}_{5}$ & $\mathbf{M n O}$ & $\begin{array}{c}\mathbf{L O} \\
\mathbf{C}\end{array}$ \\
\hline $\begin{array}{c}\text { Moszhukhinskiy } \\
\text { quarry crushed } \\
\text { stone }\end{array}$ & 66,96 & 10,84 & 0,65 & 1,58 & 0,32 & 4,71 & 2,41 & 2,47 & 2,90 & $<0,25$ & 0,07 & 0,12 & 5,62 \\
\hline $\begin{array}{c}\text { Gurievskiy } \\
\text { quarry crushed } \\
\text { stone }\end{array}$ & 26,11 & 2,89 & 0,59 & 0,25 & 0,10 & 37,11 & 0,88 & 0,83 & 0,64 & 0,47 & 0,08 & 0,09 & 29,57 \\
\hline White marble & 0,15 & - & 0,03 & - & 0,002 & 55,51 & 0,13 & 0,002 & 0,002 & 0,004 & 0,03 & 0,01 & 43,33 \\
\hline $\begin{array}{c}\text { Krapivinsky } \\
\text { quarry crushed } \\
\text { stone }\end{array}$ & 75,30 & 13,61 & 0,15 & 1,65 & 0,24 & 0,05 & 0,17 & - & - & - & - & 0,05 & - \\
\hline
\end{tabular}

Table 2. Quality of adhesion between bituminous binder and rock surface.

\begin{tabular}{|c|c|c|c|}
\hline \multirow{2}{*}{$\begin{array}{c}\text { S } \\
\text { No. }\end{array}$} & Rock & \multicolumn{2}{|c|}{ Adhesion quality evaluation } \\
\cline { 3 - 4 } & BND 90/130 & CRMB \\
\hline 1 & $2-5 \mathrm{~mm}$ fraction Koelginskoe deposit white marble & $\begin{array}{c}\text { Excellent } \\
\text { (five points) }\end{array}$ & $\begin{array}{c}\text { Excellent } \\
\text { (five points) }\end{array}$ \\
\hline 2 & $5-20 \mathrm{~mm}$ fraction Gurievskiy quarry crushed stone & $\begin{array}{c}\text { Good } \\
\text { (four points) }\end{array}$ & $\begin{array}{c}\text { Excellent } \\
\text { (five points) }\end{array}$ \\
\hline
\end{tabular}




\begin{tabular}{|c|c|c|c|}
\hline 3 & $5-20 \mathrm{~mm}$ fraction Krapivinsky quarry crushed stone & $\begin{array}{c}\text { Bad } \\
\text { (two points) }\end{array}$ & $\begin{array}{c}\text { Good } \\
\text { (four points) }\end{array}$ \\
\hline 4 & $5-10 \mathrm{~mm}$ fraction Moszhukhinskiy quarry crushed & $\begin{array}{c}\text { Bad } \\
\text { stone }\end{array}$ & $\begin{array}{c}\text { Satisfactory } \\
\text { (three points) }\end{array}$ \\
\hline
\end{tabular}

Note: CRMB - bitumen modified with crumb rubber by stages

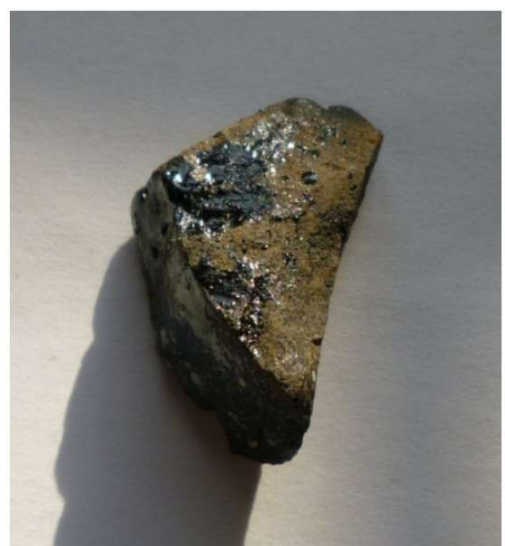

a

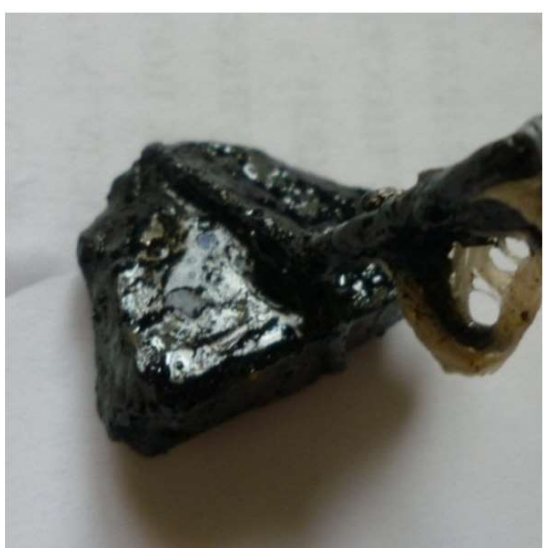

b

Fig. 1 Adhesion of: a) BND 60/90 bitumen and b) bitumen modified with crumb rubber by stages to 5-20 $\mathrm{mm}$ fraction Krapivinskiy quarry crushed stone.

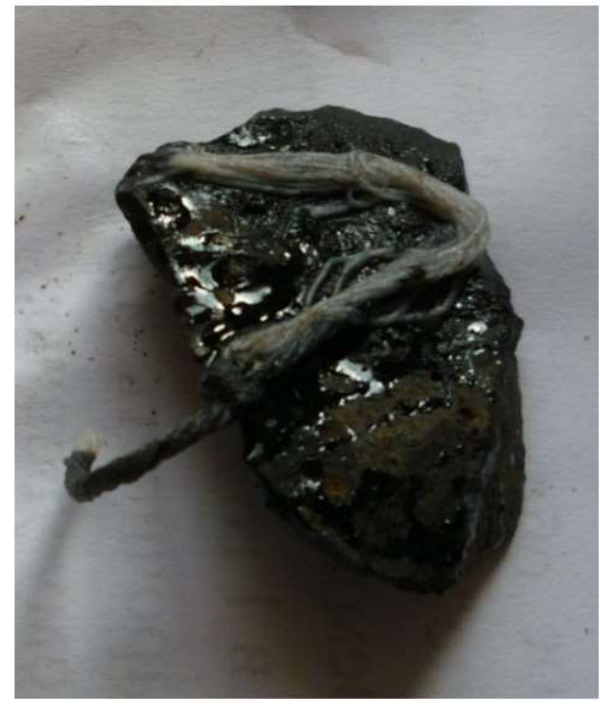

a

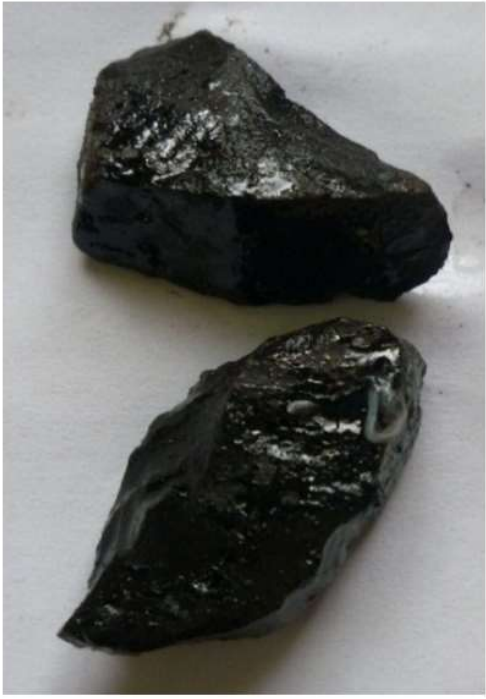

b

Fig. 2 Adhesion of bitumen modified with crumb rubber by stages to 5-10 $\mathrm{mm}$ fraction: a) Moszhukhinskiy and b) Gurievskiy quarries crushed stone.

It is known that adhesion depends on the polarity of the components (asphaltenes and maltenes). Therefore, it can be said that adhesion is due to the formation of a double electrical field at the interface between the bitumen film and the rock.

The presented rocks under study have chemical properties different from each other, which are listed in table 1 . But at the same time, the evaluated material, namely bitumen, 
modified with crumb rubber by stages contains non-dissolved parts of gel-like crumb rubber, therefore, there are several theories of adhesion formation in the studied materials.

Since the studied bitumen modified with crumb rubber by stages contains incorporates non-dissolved part of gel-like rubber crumb, it is reasonable to assume that this material interacts with the surface of mineral components through several adhesion types.

The first theory belongs to the founder of the mechanical interlocking theory of McBain. According to this theory, adhesion occurs due to the flow of the binder into the pores or cracks formed on the surface of the mineral component, followed by hardening. Thus, the strength of the adhesive joint is determined by the porosity of the rock and the strength of the binder film. However, it is worth mentioning the fact that the study of this binder revealed the so-called flagellum bridges, which occur, just because of non-dissolved rubber crumb particles, by means of which they adhere to the surface of the rocks.

The second theory proposed by De Bruyne and McLaren, which consists in determining adhesion as a result of the interaction between the binder and the surface of the rock due to intermolecular forces (adsorption theory).

The main point in this theory is that the strength of adhesive bonding occurs only in cases where the binder and the rock have polar functional groups. As it is known, bituminous binder has negatively charged particles, while, the rock is positively charged. Intermolecular attraction is realized by a complex of forces and strongly depends on the chemical nature of the interacting phases.

Analyzing the data of the chemical composition of rocks and the quality of adhesion between the binder and the rocks listed in Tables 1 and 2, it can be said that the adherence of the binder to Moszhuinskiy and Krapivinskiy quarries rock is worse than that of other samples due to the significant content of silicon oxide. As it is known, $\mathrm{SiO}^{2}$ has negatively charged ions; therefore, a unipolar bond is the cause of the insufficient interaction of two dissimilar bodies. In turn, the Koelginskiy deposit marble and the Gurievskiy quarry rock have the best adhesive properties in relation to those of other samples, due to the fact that $\mathrm{CaO}$ prevails in their amount. Calcium oxide has positively charged ions, which, in contact with the surface of rubber modified binder, being adsorbed on the surface of the rock, attracts bipolar ions, resulting in the adhesive ability of the materials under consideration.

Thus, based on theoretical assumptions, it can be concluded that adhesion cannot exist in any one form; it necessarily finds its state in the interfacial systems of interaction between several materials.

\section{Conclusions}

Based on the data presented in the table, it can be concluded that bitumen modified with crumb rubber by stages unambiguously gives a positive result with any rock of different basicity. At a minimum, rubber crumb modified bitumen increases the adhesive ability of the binder by 1 point in comparison with BND 90/130 bitumen.

By a more detailed examination of Figures 1 and 2, it can be clearly observed what surface of rock is covered by the materials under study, which with confidence indicates the improvement of its adhesive properties.

There are two adhesion theories inherent in the rubber modified binder:

1) Mechanical - occurring due to physical penetration into cracks, pores of rocks and hardening on the surface; 2) The second theory is the adsorption interaction of intermolecular bonds through the polarities of functional groups. 


\section{References}

1. B. Abdulwarith, H. Norhidayah, M. Hanif, M. Jahangir, Materials and Structures, 97 (2016)

2. M. A. Mull, K. Stuart, A. Yehia, Journal of Materials Science, 37, 557 (002)

3. H. Kim, S. Lee, S. Amirkhanian, KSCE Journal of Civil Engineering, 14, 839 (2010)

4. G. R. Morrison, S. A. Hesp, Journal of Materials Science, 30, 2584 (1995)

5. X. Chuan, L.Tianqing, Q.Yanjun, Journal of Modern Transportation, 21, 273 (2013)

6. S. Shakir, P. Jorge, M. Manuel, 7th RILEM International Conference on Cracking in Pavements, 4, 1157 (2012)

7. M. Tao, Z. Yongli, H. Xiaoming, Z. Yao, KSCE Journal of Civil Engineering, 20, 1347 (2016)

8. R.G. Hicks, D. Cheng, T. Duffy, Clifornia Pavement Preservation Center, 115, 23 (2010)

9. H. Zhu, C. Liu, K. Tom, T. Norasit, Materials and Structures, 41, 383 (2008)

10. G. Juan, A. Ana, G. Felice, Mechanics of Time-Dependent Materials, 20, 389 (2016)

11. A. A. Khristoforova, M. D. Sokolova, S. E. Filippov, B. N. Zarovnyaev, M. L. Davydova, International Polymer Science and Technology, 42:9, 27 (2015)

12. A. A. Khristoforova, M. D. Sokolova, B. N. Zarovnyaev, A. N. Akishev, Mining Journal, 3, 47 (2016) 